\title{
Adaptive design to mitigate the effects of UHI: the case study of Piazza Togliatti in the Municipality of Scandicci.
}

\author{
Rosa Romano ${ }^{1}$, Roberto Bologna ${ }^{1}$, Giulio Hasanaj ${ }^{1}$, Maria Vittoria Arnetoli ${ }^{1}$ \\ ${ }^{1}$ Florence University, Architecture Department DIDA, Florence, Italy \\ rosa.romano@unifi.it
}

\begin{abstract}
The relationship between microclimate and built environment has been explored for almost forty years, with reference not only to architecture but also to urban and to landscape design as instruments to increase the outdoor comfort. Recently, scientific studies on urban climate pay attention to Urban Heat Island (UHI) and related mitigation strategies as the main focus theme, also developing new sustainable urban design assessment methods.

Moving from these considerations, this paper aims to describe some results of the research "Adaptive design and innovative technology for resilient regeneration of urban district depending on climate change”, focused on the study of technological solutions able to improve the resilience of the built environment, also reducing the effects of the UHI. Furthermore, attention is given to the issue of urban space design, implemented as an instrument able to promote the regeneration of urban districts. In detail, this article presents two design proposals developed for Piazza Togliatti in Scandicci (Florence), analysing the results achieved (in terms of atmospheric temperature and Predicted Mean Vote) by means of the ENVIMet software.
\end{abstract}

Keywords: Adaptive design, urban heat islands, urban spaces design

\section{Introduction}

The 2030 Agenda of the United Nations recognizes that climate change is one of the greatest challenges of our age [1]. Its negative impacts undermine the ability of states to implement sustainable development and achieve goals such as inclusion, security, eradicate poverty and hunger. Surface temperature is set to increase during the 21st century in all global warming scenarios assessed by the Intergovernmental Panel for Climate Change models [2]. This will lead to an increase in extreme events such as high temperatures, heavy rainfall and drought phenomena. A lot of research has shown how discomfort linked to Urban Heat Island (UHI) occurs increasingly in anthropic settlements all over the world [3, 4]. The heat island effect, in fact, is characterised by the development of noticeably higher temperatures in our cities compared with the countryside that directly surrounds them [5]. The intensity of UHI strongly depends on the local meteorological conditions, but also on the urban characteristics, such as the type of materials used for the construction of urban spaces and buildings and the presence (or absence) of green and blue infrastructures [3, 6]. Furthermore, it is important to 
remember how the UHI has several impacts on quality of life and health of citizens, increasing the risk of mortality, especially among the weakest sections of the population [7, 8]. Finally, it contributes to: grow the building energy consumptions for cooling [9]; worsen indoor and outdoor thermal comfort [7,9]; raise the concentration of harmful pollutants in the air of our cities [9].

Starting from these considerations, the paper shows the first results of the National Research Project of Relevant Interest "Adaptive design and innovation technology for resilient regeneration of urban district depending on climate change" (PRIN AD) developed from the Universities of Reggio Calabria, Naples, Rome, Milan and Florence - aimed investigating design methodologies and technological solutions in order to promote the resilient regeneration of three Italian urban districts (located in Florence, Milan and Naples), both in terms of reducing exposure to climate risks (flooding and water deficiencies, heat waves and UHI) and in terms of social inclusion and economic sustainability. In detail, the article describes analysis and evaluations developed to increase the resilience of the Piazza Togliatti, a degraded square located in the centre of Scandicci (a little city placed in the Southwestern of Florence).

\section{Research methodology}

With reference to the research methodology developed in the frame of the PRIN AD, the study was articulated as follows: 1) pre-processing the geometric and physical features of the Togliatti square, through ENVI-met; 2) simulating the urban climate at the current state in typical UHI conditions; 3) designing of two different suitable project scenarios; 4) pre-processing the geometric and physical features of two project scenarios through ENVI-met; 5) simulating the two project scenarios; 6) analysing the results and detecting the most effective strategies in terms of attenuation of the urban heat island, overall improvement of the urban microclimate and thermal comfort.

The holistic approach is the one that inspired the design of two scenarios. We tried to avoid circumscribe the project proposal in each one, in fact, we developed the design solutions and analysed the benefits obtained within an increasing scale of project outputs. In other words, the technological solutions (shading devices, green infrastructures, etc.) proposed in the second scenario to improve the resilience of the Piazza Togliatti can be added, in a subsequent step, to the repaving strategies developed in the first one. The two scenarios, have been defined for enhancing the square's ability to react to the phenomena of climate change, included the UHI, but also with the aim of progressively transforming both its aesthetic image and its psychological perception by users, especially children and the elderly. [10]

For these reasons, we carried out ENVI-Met simulations to measure and compare two indexes of the UHI's impacts on the urban environment: atmospheric temperature $\left({ }^{\circ} \mathrm{C}\right)$ and environmental comfort (PMV index). In detail, we have used the ENVI-Met's application "Biomet", that is able to carry out the value of the PMV of a specific user whose parameters related to sex, age, height and weight are inserted. Moreover, we have considered only the climatic conditions of UHI in our analysis. Therefore, the PMV is not always included between the range -3 and +3 , but it sees higher values 
which identify worse environmental discomfort for the user that we have choose: an elderly man.

\section{The case study}

Piazza Togliatti is a large, empty and degraded rectangular space, which showed many problems of liveability, accessibility and safety, as well as a negative level of climate resilience. Currently, in the square are located the following functional destinations (fig. 1): a playground area, in the northern border; an outdoor area, in the southern border, used as a market in the morning and as parking in the rest of the day. Citizens spend a lot of time in these two spaces during the whole year, although if the environmental conditions - especially in the summer months - do not guarantee sufficient comfort. For this reason, we decided to focus our requalification projects on the regeneration of this square, in order to increase not only its environmental performances but also its social potential as aggregative space. The square is actually characterized by the following physic characteristics: pavements made with "hot" materials; green areas that appear in a fragmented composition; roads without trees and vegetation; absence of water elements; absence of green roofs or roofs made with cool materials.

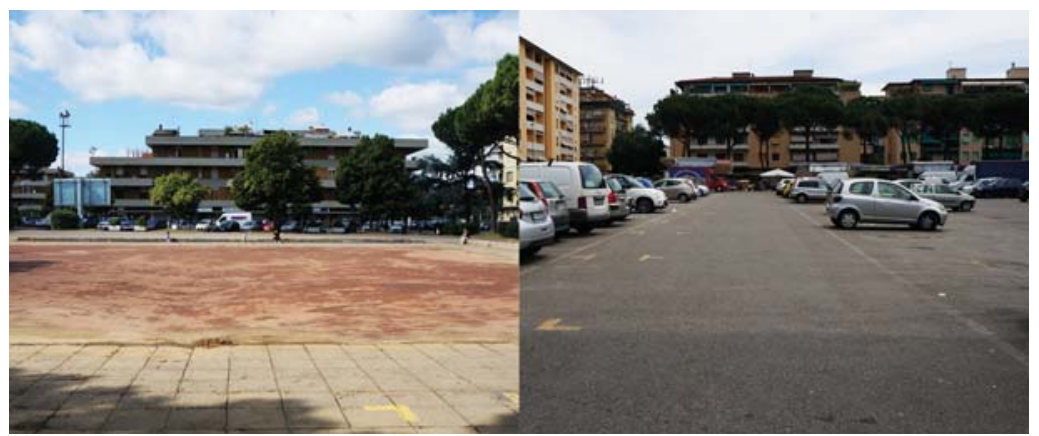

Fig. 1: Photos of Piazza Togliatti. On the left the playground area, on the right the parking and market area

\section{$4 \quad$ Simulation model}

Compared to the methodological context described above, the analysis and simulation tools were developed with multiple objectives, involving the different phases of the design process. In the case of Piazza Togliatti, the "ex-ante" energy simulations allowed us to define its behavioural profile in the existing configuration (making to emerge the critical issues and vulnerabilities, but also the potential for architectural renovation), and to analyse the benefits that each project proposal could achieve.

The urban microclimate, the atmospheric temperature $\left({ }^{\circ} \mathrm{C}\right)$ and the environmental comfort (PMV index) were calculated by ENVI-met which is a prognostic model based on the fundamental laws of fluid dynamics and thermodynamics [11]. In particular, this 
software allows to perform a microclimatic analysis starting from input climatic data of speed and mean direction of wind, and hourly course of temperature and humidity. It also provides the evaluation of the interrelation between buildings, vegetation and various surface coverings, and of their effects on the perceived microclimate [12]. The values of Fanger's indices calculated by ENVI-met are based on the modified Fanger heat balance equation developed by Jendritzky and Nubler for outdoor conditions [13].

In our research, the square model was created with the "area input file editor" rotated of $60^{\circ}$ to the North, according to the main direction of the roads. The area was rendered with a $100 \times 100 \times 30(x-y-z)$ grids, keeping the following spacing: $\mathrm{dx}=3.00 \mathrm{~m}$; $\mathrm{dy}=$ $3.00 \mathrm{~m} ; \mathrm{dz}=2.00 \mathrm{~m}$. 10 buildings were included in the model with a height between 6 and $24 \mathrm{~m}, 15 \mathrm{~m}$ being the mean value. For the modelling of the vegetation, eight different trees types were employed (tab. 1).

Table 1. Principal features of 3D plants included in the model simulation

\begin{tabular}{llllllll}
\hline $\begin{array}{l}\text { Plants fea- } \\
\text { tures }\end{array}$ & $\begin{array}{l}\text { Acer } \\
\text { negundo }\end{array}$ & $\begin{array}{l}\text { Pinus } \\
\text { pinea }\end{array}$ & Cypress & $\begin{array}{l}\text { Populus } \\
\text { alba }\end{array}$ & Tilia & $\begin{array}{l}\text { Populus } \\
\text { nigra }\end{array}$ & Privet \\
\hline Height (m) & 11 & 15 & 7 & 7 & 25 & 18 & 20 \\
Width (m) & 9 & 11 & 3 & 5 & 15 & 13 & 15 \\
Albedo & 0.5 & 0.6 & 0.3 & 0.7 & 0.18 & 0.4 & 0.4 \\
\hline
\end{tabular}

Furthermore, the model was kicked off especially regarding radiative properties of surface materials and of the two design scenarios (tab. 2). Finally, into the model was included a part of the urban context near the square, since the software has some difficulties of execution of the calculations in the proximity of the edges.

Table 2. Materials in the current status and scenarios, with their albedo value

\begin{tabular}{lllll}
\hline Materials & Albedo & Current status & Scenario 1 & Scenario 2 \\
\hline Asphalt & 0.1 & $\checkmark$ & $\checkmark$ & $\checkmark$ \\
Brick & 0.3 & $\checkmark$ & & \\
Dark concrete & 0.2 & $\checkmark$ & $\checkmark$ & \\
Red asphalt & 0.5 & $\checkmark$ & & \\
Loamy soil & 0.15 & $\checkmark$ & $\checkmark$ & $\checkmark$ \\
Grey concrete & 0.5 & & $\checkmark$ & $\checkmark$ \\
Beaten heart & 0.8 & & $\checkmark$ & $\checkmark$ \\
Grass & 0.2 & & $\checkmark$ & \\
\hline
\end{tabular}

Thanks to the collaboration with the Florence Institute of Biometeorology, the climatic data of the last 25 years were analysed [14], identifying the hottest day on 21 August 2011: Temperature minimum $20.7^{\circ} \mathrm{C}$ at 6:00 a.m.; Temperature maximum 41 ${ }^{\circ} \mathrm{C}$ at 04:00 p.m.; Humidity minimum $14 \%$ at $01: 00$ p.m.; Humidity maximum $66 \%$ at 6:00 a.m.; $0.2 \mathrm{~m} / \mathrm{sec}$ wind speed from south direction. 
The outputs related to atmospheric temperature and Predicted Mean Vote (PMV), were extrapolated for the worst microclimatic conditions (04:00 p.m.) and with the parameters of the more disadvantaged users, represented by elderly men (age 70 years).

\section{$5 \quad$ Investigated scenarios}

The impact of the main technological strategies, developed in the frame of the PRIN $\mathrm{AD}$ research in order to decrease the UHI effects, was evaluated, analysing the energy performances of three different model configurations (fig. 2) listed below:

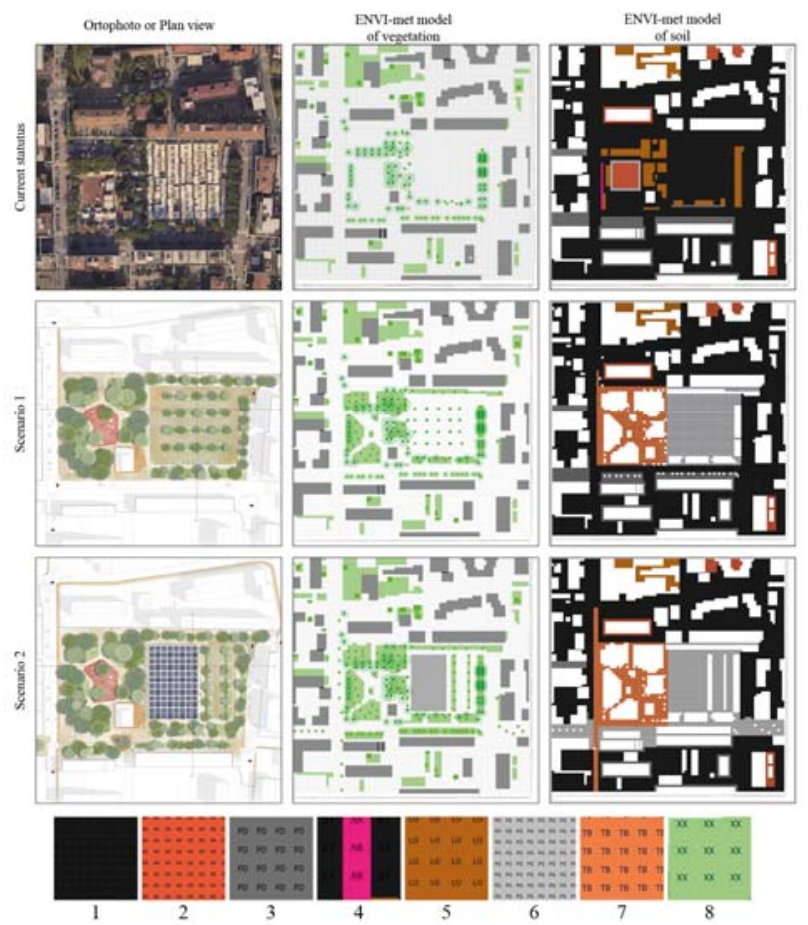

Fig. 2: Analysis of surface vegetation and soil in the current status and in the two scenarios. Legend of materials used in the models: 1 asphalt, 2 brick, 3 dark concrete, 4 red asphalt, 5 loamy soil, 6 grey concrete, 7 beaten heart, 8 grass.

\section{Base Case}

The model was kicked off applying specific values of the urban environment of Piazza Togliatti, described in detail in the previous paragraph 4.

\section{Scenario 1}

The project developed in the first scenario aimed to improve the environmental and social features of the square, without changing its actual uses and functions. For this reason, the retrofitting project concerned only the repaving action to create green 
spaces, in particularly planting new trees in the parking-market zone. The materials for the repaving were chosen with a higher albedo then those existing. In order to build this simulation in ENVI-Met the same Input files of the Base Case were employed, modifying only the Configuration File, which contains all the parameters set to the model.

\section{Scenario 2}

The project developed in the second scenario, starting from the repaving of the square (as done in the first scenario), was focused on: 1) the construction of solar shading devices in the parking-market area, where will be possible to integrate technologies for producing renewable energy and to collect water; 2 ) the requalification of the bordering streets, converted to green corridors; 3 ) the use of water, integrating in the urban space of Piazza Togliatti a blue infrastructure in order to increase its outdoor comfort especially in the summer months. Radiative properties were almost the same as Base Case. Also in this case, a different Configuration File (as for Scenario 1) was used.

\section{$6 \quad$ Results}

\subsection{Atmospheric temperature and PMV index}

All the simulations were started on 21 August 2011 and the elapsed time was $24 \mathrm{~h}$. In the fig. 3 are presented thermal and PMV maps of the three scenarios analysed for the warmest moment of the day (04:00 p.m.). For horizontal views (x-y) all data are shown at pedestrian level-height $(\mathrm{z}=1.80 \mathrm{~m}$, representing what people could perceive).

The results achieved with the simulations can be summarised as follows:

\section{Base Case}

The central area of the playground and of the parking-market zone are the hottest spaces into the square, due to the presence of asphalt and dark concrete, and to the lack of vegetation, trees and shading devices. The maximum temperature is $41.17^{\circ} \mathrm{C}$, while minimum, recorded in densely vegetated areas, is $35.83^{\circ} \mathrm{C}$. The PMV index shows a minimum value of 3.73 and a maximum of 6.94 .

\section{Scenario 1}

In this scenario, the maximum temperature is $41.06{ }^{\circ} \mathrm{C}$, the minimum temperature is $35.56^{\circ} \mathrm{C}$ as usual recorded in the green areas. As shown in fig. 4 , a temperature reduction is achieved, due to the repaving strategies and the planting of new vegetation. The PMV index shows a minimum value of 3.67 and a maximum of 6.86, with a maximum reduction of -1.97 (fig. 5) compared to the base case. The best results, in terms of temperature and PMV index, are recorded in correspondence of the central area of parkingmarket, where we have proposed to replace the existing dark pavement with cool materials and in addition to planting 20 new trees in order to increase the shading areas. 


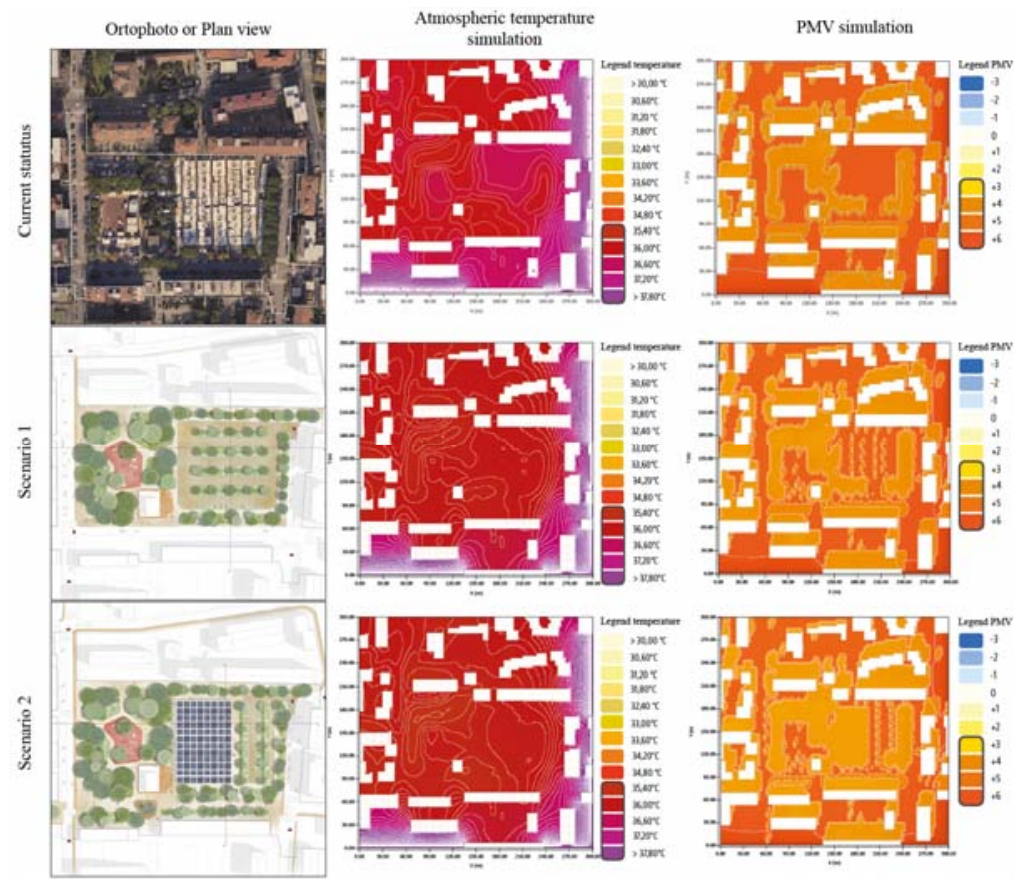

Fig. 3: From left to right: Square plan views; Atmospheric temperature and PMV of elderly men (70 years old)

\section{Scenario 2}

In this scenario Maximum temperature is $40.99^{\circ} \mathrm{C}$., Minimum temperature is $35.39^{\circ} \mathrm{C}$. As shown in fig. 4 a general decrease in the temperature is recorded, but it is deeper than in the first one. In detail in the covered area of the parking-market the atmospheric temperature is reduced of $-0.74{ }^{\circ} \mathrm{C}$, thanks to the presence of the shading adaptive devices. Further, the PMV index shows a minimum value of 3.60 and a maximum of 6.83 , with a maximum reduction compared to the base case of -2.23 (fig. 5).
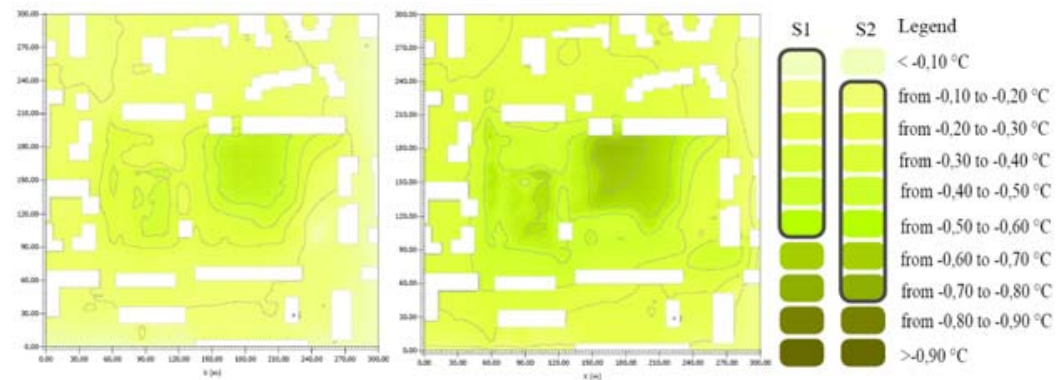

Fig. 4. ENVI-Met ${ }^{\circledR}$ comparisons of the decreasing of atmospheric temperature in the scenario 1 and 2, $\mathrm{x}-\mathrm{y}$ view at $\mathrm{z}=1.80 \mathrm{~m}$, at 04:00 p.m., 21 August 2011 

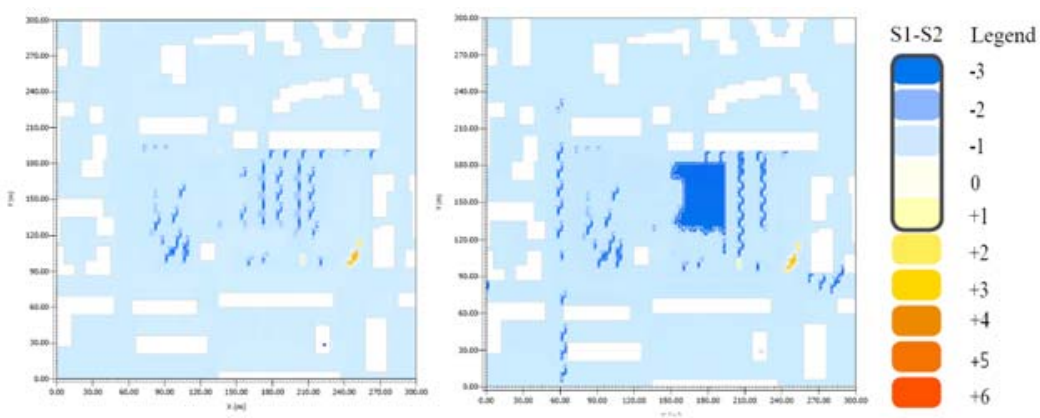

Fig. 5. ENVI-Met ${ }^{\circledR}$ comparisons of PMV simulation in the two scenarios; $x-y$ view at $z=1.80$ m, at 04:00 p.m., 21 August 2011, parameters for PMV of elderly men (70 years old)

\subsection{Hourly temperature profile of two selected spots.}

To better understand temperature oscillation simulated by ENVI-Met, and in order to compare the temperature in the different square areas, we selected two different points located in correspondence of the playground (fig. 6) and of the parking-market (fig. 7). Furthermore, we plotted an hourly temperature profile among the simulation period, using temperatures output by the software.

In this focused analysis, Scenario 2 guarantees achieving the best results, in terms of reduction of UHI phenomenon, in both spot points. Furthermore, it is interesting to note that the atmospheric temperature decreases in Scenario 2 also in the playground area, although the design proposal for this zone is the same as Scenario 1. In other words, the simulation showed that increasing shading surfaces allowed reducing the atmospheric temperature throughout the project area, improving the urban microclimate also in the zone not directly involved in the regeneration actions.

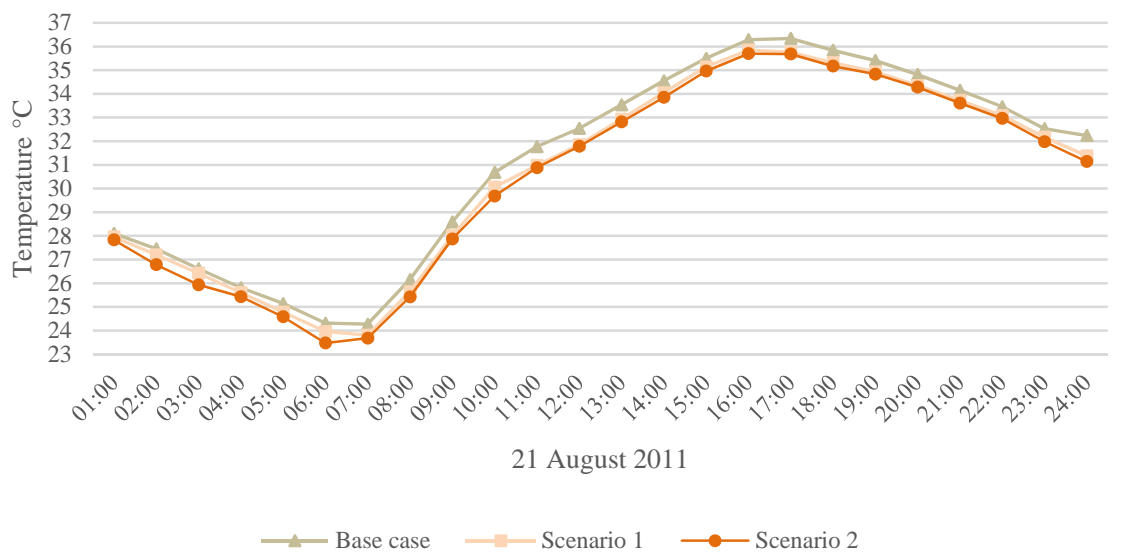

Fig. 6. Hourly temperature profile of the selected spot situated in the playground area, at $\mathrm{z}=1.80$ m, at 04:00 p.m., 21 August 2011 


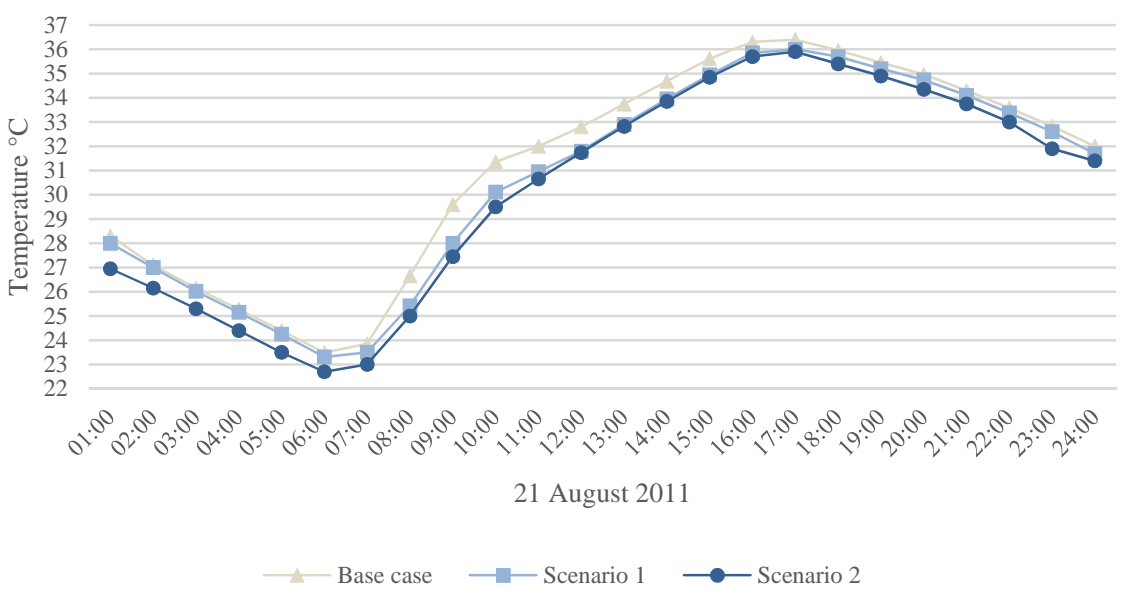

Fig. 7. Hourly temperature profile of the selected spot situated in the market area, at $\mathrm{z}=1.80 \mathrm{~m}$, at 04:00 p.m., 21 August 2011

\section{Conclusions}

As mentioned above, in recent decades, urbanization and regional climate changes have been occurring rapidly on a worldwide scale. Of the many aspects that are influencing the quality of urban life, one of the most essential aspects is that of the microclimate of urban areas. In these circumstances, the value of the UHI has probably increased due to a variety of factors (building features and materials; more traffic and industrial activities; higher energy consumption, etc.). Accordingly, UHI mitigation strategies have been implemented in various sustainable cities around the world [15].

These strategies include identifying opportunities for urban greening, following the concept of the resilient and adaptive public spaces, which contribute to the improvement of urban environmental quality. Further, the creation of new green spaces and corridors promotes the image of the city and contributes improving the lives of its citizens. When a public space needs to be renovated anyway, measures against heat accumulation can be combined with other measures that are necessary to improve the social, physical or economic condition [16].

Our study shows how it is possible to redevelop the urban space, using technological solutions that are actually able to improve the microclimate, reducing the atmospheric temperature and the PMV index, but also change its spatial and geometric configuration. Sample technological solutions (as repaving with cool materials, green and blue infrastructures, shading devices) can be implemented in a systemic way and stand a good chance of reducing the ill effects attendant upon the occurrence of UHI in the built environment. Finally, the possibility to use simulation tools allows the designers and the Public Administrations to know exactly the achievable results of these strategies. 


\section{References}

1. United Nations, Transforming our world: the 2030 Agenda for development, https://sustainabledevelopment.un.org/content/documents/21252030\%20Agenda\%20for\%20Sustainable\%20Development\%20web.pdf

2. IPCC: Climate Change 2014: Impacts, Adaptation, and Vulnerability. Part A: Global and Sectoral Aspects. Contribution of Working Group II to the Fifth Assessment Report of the Intergovernmental Panel on Climate Change. Cambridge University Press, Cambridge, United Kingdom and New York, (2014).

3. Akbari H., Cartalis C., Kolokotsa D., Muscio A., Pisello A. L., Rossi F., Santamouris M., Synnefa A., H. Wong N., Zinzi M.: Local climate change and urban heat island mitigation techniques - the state of the art. Journal of Civil Engineering and Management, 22:1, 1-16 (2016).

4. Grimmond, C. S. B., Ward, H. C., Kotthaus, S.: How is urbanization altering local and regional climate? In: Seto, K. C. Solecki, W. D. and Griffith, C. A. (eds.) The Routledge Handbook of Urbanization and Global Environmental Change. Routledge (2016).

5. Santamouris M., Energy and Climate in the Urban Built Environment, Routledge, Abingdon-on-Thames, UK. (2013)

6. Dessì V., Urban materials for comfortable open spaces. World Renewable Energy Congress - Sweden; 8-13 May; 2011; Linköping; Sweden. pp. 3300-3307, (2011).

7. Armstrong, B.G., Chalabi, Z., Fenn, B., Hajat, S., Kovats, S., Milojevic, A., Wilkinson, P.: Association of mortality with high temperatures in a temperate climate: England and Wales. J. Epidemiol. Commun. Health 65, 340-345, (2011).

8. Hajat, S., O’Connor, M., Kosatsky, T.: Health effects of hot weather: from awareness of risk factors to effective health protection. The Lancet, 375, 9717, 856-863, (2010).

9. Santamouris, M.: Regulating the damaged thermostat of the cities - Status, impacts and mitigation strategies, Energy and Buildings 91: 43-56, (2015).

10. Arnetoli M. V., "Climate resilience and urban regeneration. Innovative methods and tools for the project: the case study of public spaces in Scandicci”, Degree Thesis, Department of Architecture, University of Florence (2018)

11. Ambrosini, D., Galli, G., Mancini, B., Nardi, I., Sfarra, S.: Evaluating Mitigation Effects of Urban Heat Islands in a Historical Small Center with the ENVI-Met ${ }^{\circledR}$ Climate Model. Sustainability, 6, 7013-7029 (2014).

12. Evola G., Gagliano A., Fichera A, Marletta L., Martinico F., Nocera F., Pagano A., UHI effects and strategies to improve outdoor thermal comfort in dense and old neighbourhoods, Energy Procedia 134 (2017) 692-701

13. Jendritzky G., Nübler W., A model analysing the urban thermal environment in physiologically significant terms. Arch. Met. Geoph. Biokl., ser. B., 29, 31: 313-326

14. Crisci A., Morabito M. \& Nardino M. (2018). UNIFI IBIMET PRIN 2015 CLIMATIC DATABASE (Version 1.0) [Data set]. Zenodo. http://doi.org/10.5281/zenodo.1292130

15. Rehan r. M.: Cool city as a sustainable example of heat island management case study of the coolest city in the world, HBRC Journal, 12, 191-207 (2016)

16. Kleerekoper L., van Esch M., Baldiri Salcedo T., How to make a city climate-proof, addressing the urban heat island effect. Resources, Conservation and Recycling, 64, 30- 38 (2012) 